\title{
The PTEN and ATM axis controls the G1/S cell cycle checkpoint and tumorigenesis in HER2-positive breast cancer
}

\author{
Christian Bassi $^{1,3} \cdot$ Jerome Fortin $^{1} \cdot$ Bryan E. Snow $^{1} \cdot$ Andrew Wakeham $^{1} \cdot$ Jason Ho ${ }^{1} \cdot$ Jillian Haight $^{1}$.

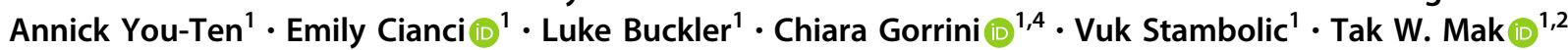

Received: 2 November 2020 / Revised: 22 April 2021 / Accepted: 23 April 2021 / Published online: 31 May 2021

(c) Crown 2021. This article is published with open access

\begin{abstract}
The tumor suppressor PTEN is disrupted in a large proportion of cancers, including in HER2-positive breast cancer, where its loss is associated with resistance to therapy. Upon genotoxic stress, ataxia telangiectasia mutated (ATM) is activated and phosphorylates PTEN on residue 398. To elucidate the physiological role of this molecular event, we generated and analyzed knock-in mice expressing a mutant form of PTEN that cannot be phosphorylated by ATM (PTEN-398A). This mutation accelerated tumorigenesis in a model of HER2-positive breast cancer. Mammary tumors in bi-transgenic mice carrying MMTV-neu and Pten ${ }^{398 A}$ were characterized by DNA damage accumulation but reduced apoptosis. Mechanistically, phosphorylation of PTEN at position 398 is essential for the proper activation of the S phase checkpoint controlled by the PI3K-p2 $7^{\text {Kip1 }}$-CDK2 axis. Moreover, we linked these defects to the impaired ability of the PTEN-398A protein to relocalize to the plasma membrane in response to genotoxic stress. Altogether, our results uncover a novel role for ATM-dependent PTEN phosphorylation in the control of genomic stability, cell cycle progression, and tumorigenesis.
\end{abstract}

\section{Introduction}

PTEN contains an N-terminal phosphatase domain that can dephosphorylate a component of the lipid cellular membrane, phosphatidylinositol 3,4,5-trisphosphate $\left(\mathrm{PI}(3,4,5) \mathrm{P}_{3}\right.$ or $\mathrm{PIP}_{3}$ ) [1]. By dephosphorylating the $\mathrm{D} 3$ position of $\mathrm{PIP}_{3}$,

Edited by G. Melino

Supplementary information The online version contains supplementary material available at https://doi.org/10.1038/s41418021-00799-8.

Tak W. Mak

tak.mak@uhnresearch.ca

1 Princess Margaret Cancer Centre, University Health Network, 610 University Ave, Toronto, ON M5G 2C1, Canada

2 Department of Pathology, Centre of Oncology and Immunology, The University of Hong Kong, Hong Kong, China

3 Present address: Epigenetics and Genome Stability Team, The Institute of Cancer Research, 237 Fulham Road, London SW3 6JB, UK

4 Present address: Paediatric Solid Tumour Biology and Therapeutics Team, The Institute of Cancer Research, 15 Cotswold Road, Sutton, London SM2 5NG, UK
PTEN antagonizes the phosphatidylinositide 3-kinase (PI3K) pathway $[1,2]$. The PI3K pathway regulates diverse cellular processes, including cell metabolism, survival, proliferation, apoptosis, growth, and migration. These fundamental cellular processes, when deregulated, can contribute or drive a malignant phenotype.

Somatic loss of function mutations of PTEN are found in a variety of human cancers including breast, endometrial carcinoma, glioblastoma multiforme, skin, and prostate cancers [3]. PTEN loss is a frequent event in breast cancer and is closely associated with accelerated progression and poor prognosis [4]. In particular, the expression of PTEN has been proposed to play an important role in human epidermal growth factor receptor 2 (HER2)-overexpressing breast cancers [5]. HER2 is a member of the epidermal growth factor receptor family which possess tyrosine kinase activity [6]. Its overexpression, observed in approximately 15-20\% of breast cancer cases [7], is correlated with aggressive clinical behavior and poor prognosis [8]. Trastuzumab, a monoclonal antibody that binds with high affinity to the extracellular domain of HER2, is an effective therapy in HER2-positive breast cancer patients. The overall response rate reaches approximately $70 \%$ when PTEN expression is detected, but only about $20 \%$ for patients with negative PTEN expression $[9,10]$. 
PTEN loss of function is often associated with genomic instability $[11,12]$. Moreover, genetic deletion of PTEN in mouse embryonic fibroblasts (MEFs) causes accumulation of unrepaired DNA double-strand breaks [13]. PTEN loss is thought to contribute to genome integrity via at least two molecular mechanisms [14, 15]. In the nucleus, PTEN associates with the centromeric binding protein CENP-C and promotes kinetochore assembly and the metaphase-toanaphase transition [13]. Further, acting as a co-factor for the transcription factor E2F1, nuclear PTEN appears to regulate the expression of Rad51, a key component of the DNA repair machinery [13]. However, follow-up work [16] has yielded inconsistent results, suggesting that PTEN regulation of RAD51 at the transcriptional level might be restricted to specific cell-contexts.

PTEN deficiency alter multiple cell cycle checkpoints, possibly leaving less time for DNA damage repair and/or chromosome segregation [16]. Progression through the cell cycle requires the flawless execution of several molecular processes performed in a timely manner to ensure a proficient, and error-free, cell division. The pace at which these events occur is dictated by the activity of cyclin-dependent kinases (CDKs), which phosphorylate key substrates to promote DNA synthesis and mitotic progression. The catalytic activity of CDKs is regulated by cell cycle checkpoints that monitor the orderly execution of the major events of the cell cycle. Checkpoints represent fail-safe mechanisms which ensure that cell division is licensed only when optimal circumstances are met [17]. Proper genome maintenance through cell division cycles is required for all organisms to ensure normal reproduction, development, and prevention of diverse diseases including cancer. DNA damage can arise from endogenous processes such as DNA mismatches that are occasionally introduced during DNA replication, DNA strand breaks caused by abortive topoisomerase I and topoisomerase II activity, or from ROS produced from normal metabolic byproducts that can attack DNA. Exogenous sources mainly include mutagenic chemicals, ultraviolet and ionizing radiations (IR). Cell cycle checkpoints are capable of detecting the DNA lesions, signal their presence, and activate pathways that delay cell cycle progression, repair the DNA lesions, or eliminate the genetically unstable cells by inducing cell death [18-23].

At the core of the DNA damage response (DDR) signaling in mammalian cells are the protein kinases Ataxia telangiectasia mutated (ATM) and ATM- and RAD3-related (ATR). ATM and ATR phosphorylate and activate two other kinases, CHK1 and CHK2 which, together with ATM and ATR, are the master regulator of the cell-cycle checkpoints [24]. By regulating the activity of CDKs, these molecules slow down or arrest the cell cycle progression at the $\mathrm{G}_{1}-\mathrm{S}$, intra-S and $\mathrm{G}_{2}-\mathrm{M}$ phases to allow DNA damage to be repaired. Concomitantly, ATM and ATR promote
DNA repair by controlling the expression, activity, or recruitment of diverse factors to sites of DNA damage. Generally, the DDR machinery is able to repair the DNA damage that a cell may accumulate during its life cycle, but if the extent of the damage is deemed too high, cell death by apoptosis or cellular senescence is induced [25, 26].

In our previous work, we discovered that ATM phosphorylates PTEN at position 398 (threonine in human; serine in mouse) upon activation of the DDR [27]. To understand the biological implications of PTEN phosphorylation by ATM, we generated a mouse model that constitutively expresses a mutated form of PTEN that cannot be phosphorylated by ATM, substituting serine for alanine at position 398 (PTEN-398A). Expression of PTEN-398A caused acceleration of tumor development and progression in a well-established mouse model of HER2-positive brea st cancer [28]. Using a molecular biology approach, we identified a novel mechanism by which the phosphorylation of PTEN by ATM regulates its cellular redistribution and contributes to the tumor suppressor function of the protein.

\section{Materials and methods}

\section{Construction of Pten $^{398 A}$ targeting vector}

A targeting construct was designed to replace the last exon of Pten with a version in which serine 398 was mutated to alanine along with the creation of a silent SphI restriction site. To generate the short-arm and long arm genomic targeting fragments, we designed primers based on mouse Pten genomic sequence (GenBank Accession No. NC_000085) to use in polymerase chain reaction (PCR) from mouse 129J genomic DNA (Jackson Laboratory, Bar Harbor, Maine). In brief, PCR primers 5'-AGT CGA CAT GTG CCT CAA TGC TTG TCT AAC ATG AGA AAT GC-3' (Pten Sall sense) and 5'-CCT CGA GAA GCT TAT AAT TCT ATA AAA GTG CAA ACT GAA GGC AAT G-3' (Pten HindIII antisense) were used to amplify a $978 \mathrm{bp}$ short-arm fragment (corresponding to mPten intron 8) from $200 \mathrm{ng}$ of $129 \mathrm{~J}$ genomic DNA using the Expand ${ }^{\mathrm{TM}}$ High Fidelity PCR system (Roche). The Expand ${ }^{\mathrm{TM}}$ Long Template PCR system (Roche $\mathrm{GmbH}$, Germany) was used to amplify a $4.2 \mathrm{~kb}$ long arm fragment (corresponding to the entire mPten exon 9 coding region and part of the $3^{\prime} \mathrm{UTR}$ ) from 129J Genomic DNA using the PCR primers 5'-TGC GGC CGC GAA TTT TGT GAT TTA GTG AGT TCA TTG CCT TCA G-3' (Pten NotI sense) and 5'-GCG GCC GCC TAC TAC TCT GGA CAA GTC CCG ATG AAA CC-3' (Pten NotI antisense). The resulting PCR products were gel-purified using the Nucleospin ${ }^{\circ} \mathrm{Gel}$ and PCR Clean-up system (Machery-Nagel Gmbh \& Co., Germany), 
TA-cloned into pCR2.1-TOPO (Invitrogen, San Diego, $\mathrm{CA}$ ), and subcloned into a modified pBluescript II KS (Stratagene, La Jolla, CA) vector containing a PGKneomycin cassette flanked by both FRT and LOXP sequences. A diphtheria toxin (DTA) gene was inserted $3^{\prime}$ of the long arm to negatively select against non-homologous targeting. Insert sequence was validated using fluorescent dideoxy-nucleotide sequencing and automated detection (ABI/Perkin Elmer, Forest City, CA).

\section{Pten $^{398 A}$ mutagenesis}

To mutate serine at position 398 of Pten, a S to A mutation of amino acid 398 and silent SphI restriction site was introduced in exon 9 of the $3^{\prime}$ long arm by changing 1 basepair (TCA to GCA) by site-directed mutagenesis with the Quick Change mutagenesis II ${ }^{\mathrm{TM}}$ system (Stratagene, La Jolla, CA). The primers used for creation of the 398A and silent SphI site were: PTEN_398A_U1: 5'-GAA CCT TTT GAT GAA GAT CAG $C A T G C A$ CAA ATT ACA AAA GTC TG-3' and PTEN_398A_L 1 1: 5'-CAG ACT TTT GTA ATT TGT GCA TGC TGA TCT TCA TCA AAA GGT TC- ${ }^{\prime}$. The PCR-generated mutagenized fragment was completely sequenced in order to verify the sequence.

\section{Targeted disruption of the murine Pten gene in ES cells}

The Pten $^{398 A}$ targeting vector $(25 \mu \mathrm{g})$ was linearized with SalI restriction endonuclease at the short arm and electroporated into E14 ES cells (derived from the R129J strain) using a Bio-Rad Gene Pulser, $0.34 \mathrm{kV}$, and $0.25 \mathrm{mF}$. ES cell culture was carried out as previously described [29]. After G418 selection $(250 \mu \mathrm{g} / \mathrm{ml})$, homologous recombinants were identified by $5^{\prime}$ and $3^{\prime}$ flanking PCR and confirmed by Southern blot analysis and sequencing following published protocols [29]. Homologous recombination (HR) at the $5^{\prime}$ short-arm was confirmed by Terra ${ }^{\mathrm{TM}}$ PCR Direct (Takara Bio, Mountain View, CA, USA) amplification of a $1680 \mathrm{bp}$ fragment using the primers mPten Ex8 Sense: 5'-GCA AAC AAA GAC AAG GCC AAC CGA TAC TTC-3', in exon 8 of Pten, and the vector-specific primer $K I \_5 \_P C R \_a n t i-$ sense: 5'-CGT CAA CCA AGC TCT GAT AGA GTT GCT CAA GG- $3^{\prime}$. HR at the $3^{\prime}$ long-arm and sequence validation of the 398A was confirmed by Terra ${ }^{\mathrm{TM}}$ PCR Direct amplification of a $4395 \mathrm{bp}$ fragment using the vector-specific primer KI_3_PCR_sense: 5'-GAG TGC GAT CTA GCC AGA CGA GGG TTC- $3^{\prime}$ and the Pten $3^{\prime}$ UTR primer: PTEN_UTR_antisense 5'-CAA CTT CAT GTA ACA TTA AGA CTC CAC ATT GAC- $3^{\prime}$.

HR of the targeting vector with the endogenous locus results in insertion of a novel HindIII site into the Pten locus, thus allowing the targeted and wild-type alleles to be distinguished by Southern analysis with the $867 \mathrm{bp} 5^{\prime}$ flanking genomic probe $\left(5^{\prime}\right.$ Probe). The $\sim 9 \mathrm{~kb}$ HindIII fragment corresponding to the wild-type allele is decreased to $\sim 4.5 \mathrm{~kb}$ upon disruption of the Pten locus by integration of the Neomycin resistance gene. The $5^{\prime}$ Flanking Probe was generated by PCR using the primers $5^{\prime}$-GCT GCT AGA GTC TAG TCT TAG AAC TTA CTG TTT G-3' ${ }^{\prime} 5^{\prime}$ Probe sense) and $5^{\prime}$-TAC TAT TAC TTC TTC ACA ACC ACT TCT TTC AAC-3' (5'Probe antisense). Genomic DNA was digested with HindIII, resolved on an agarose gel, transferred to Hybond $\mathrm{N}+$ membrane, and hybridized to ${ }^{32} \mathrm{P}$ labeled Pten 5' Probe.

\section{Generation of Pten ${ }^{5398 A}$ mice}

Chimeric mice were produced by microinjection of independent Pten ${ }^{\text {S398A }}$ ES cell clones into E3.5 C57BL/6J blastocysts and transferred to ICR pseudopregnant foster mothers. Chimeric males were mated with C57BL/6J females (Jackson Laboratory). Germ line transmission of the mutant allele was confirmed by PCR and Southern blot analysis of tail DNA from mice with an agouti coat color. The PGK-Neo cassette was removed by crossing with Flpdeleter mice (Jackson Laboratory stock \#009086) [30] and PCR genotyping and sequence validation of recombination at the FRT sites.

All experimental procedures strictly adhered to the Canadian Council on Animal Care guidelines.

\section{Antibodies}

The following antibodies were purchased from Cell Signaling Technology: PTEN (138G6) (\#9559), Akt (\#9272), phospho-Akt (Ser473) (193H12) (\#4058). Phospho-p27 ${ }^{\text {Kip1 }}$ (phospho T157) was purchased from abcam (ab85047). Phospho-Histone H2A.X (Ser139) (JBW301) (05-636) was from Millipore. Antibody against 53BP1 (A300-272A) was from Bethyl Laboratories.

\section{Cell culture, viral infections, and reagents}

MCF10A PTEN-398A and isogenic MCF10A PTEN-WT cells were maintained in DMEM/F-12 (1:1), supplemented with $10 \%$ fetal bovine serum (Gibco), Pen/Strep (100 mg/ $\mathrm{ml})$, insulin $(5 \mu \mathrm{g} / \mathrm{ml})$, hydrocortisone $(1 \mu \mathrm{g} / \mathrm{ml})$ (all from Sigma), and EGF (5 ng/ml, Peprotech).

For expression in MCF10A cells, PTEN and PTEN-398A were cloned into pBabe-Flag as described in Bassi et al. [27]. Viral transduction with retroviruses expressing FLAGPTEN or FLAG-PTEN-398A was performed in MCF10A cells by following the procedures described previously [31]. Z-VAD-FMK was from MedKoo Biosciences (Catalog \#533011). 


\section{Cell lysis, immunoblotting, and immunoprecipitations}

Unless indicated otherwise, for immunoblotting cells were lysed in Laemmli sample buffer (60 mM Tris-Cl pH 6.8, $2 \%$ sodium dodecyl sulfate, $10 \%$ glycerol, $5 \% \beta$-mercaptoethanol), normalized for total protein content, resolved by sodium dodecyl sulphate-polyacrylamide gel electrophoresis, and transferred to PVDF membranes (Millipore). Membranes were blocked in Odyssey ${ }^{\circ}$ Blocking Buffer (LIcor) and probed with the indicated antibodies.

For immunoprecipitations, cells were lysed for $30 \mathrm{~min}$ on ice in IP buffer $(150 \mathrm{mM} \mathrm{NaCl}-50 \mathrm{mM}$ Tris $\mathrm{pH} 7.4-10 \%$ glycerol-1\% Triton-X 100), supplemented protease inhibitor cocktail (Sigma). Insoluble material was removed by centrifugation at $15,000 \times g$ for $15 \mathrm{~min}$ at $4{ }^{\circ} \mathrm{C}$. Immunoprecipitations were performed by gentle rotation overnight at $4{ }^{\circ} \mathrm{C}$, and then immune complexes were washed four times in cold IP buffer and resuspended in Laemmli buffer.

\section{Immunofluorescence}

Cells cultured on glass cover slips were rinsed in phosphatebuffered saline (PBS), fixed with $3.7 \%$ formaldehyde in PBS for $10 \mathrm{~min}$ at room temperature, permeabilized with PBS plus $0.5 \%$ Triton X-100 for 5 min, blocked overnight at $4{ }^{\circ} \mathrm{C}$ with PBS containing $1 \%$ bovine serum albumin (Fisher), and then incubated with primary antibodies (PTEN Cell signaling 9559, 1:200; 53BP1 Bethyl A300-081A 1:500; $\gamma \mathrm{H} 2 \mathrm{AX}$ Millipore 05-636 1:1000). After 3 washes with PBS, $5 \mathrm{~min}$ each, at room temperature, samples were incubated for $30 \mathrm{~min}$ with a 1:400 dilution (in PBS) of goat anti-rabbit or anti-mouse IgG conjugated to the fluorescent Alexa 488 dye,goat anti-mouse $\operatorname{IgG}$ conjugated to the fluorescent Alexa 546 dye, or donkey anti-rabbit conjugated to the fluorescent Alexa 647 dye (Invitrogen Molecular Probes), washed three times, stained with DAPI and mounted in Mowiol.

\section{Cell proliferation assays}

Cell number was assessed indirectly by using the Sulforhodamine B (SRB) assay [32].

\section{HR assays}

HR and NHEJ assay were performed as described in Weinstock et al. [33] MCF10A cells (PTEN 398A and PTEN WT) were stably transduced with differentially mutated green fluorescent protein (GFP) and with pCMV3xnlsI-SceI, using Amaxa $^{\text {TM }}$ Nucleofector $^{\text {TM }}$ Technology (Lonza). At 2 days post transfection, GFP signals were acquired using a FACSCanto II flow cytometer instrument and analyzed using FACSDiva and FlowJo software (BD Biosciences). Recombination efficiency was calculated as the number of GFP-positive cells in the samples divided by the number of GFP-positive cells in MCF10A PTEN-WT cells. For each experiment, 10,000 cells were scored per treatment group.

\section{Cell cycle analysis}

Cell cycle analysis was carried out by flow cytometry. Briefly, MCF10A cells were seeded into 6-well culture plates, treated as indicated, collected, fixed, stained with propidium iodide $(100 \mu \mathrm{g} / \mathrm{mL})$ and RNAse $(20 \mu \mathrm{g} / \mathrm{mL})$ in PBS for $1 \mathrm{~h}$, acquired on a FACSCanto II flow cytometer instrument and analyzed using FACSDiva and FlowJo software (BD Biosciences). Similarly, indirect immunofluorescence on ethanol-fixed MCF10A cells (70\% in PBS) was performed to quantify mitotic cells using an antiphospho-H3 (Ser10) specific antibody (CellSignaling) detected by an Alexa488-labeled goat anti-rabbit secondary antibody (Invitrogen). Cells were acquired on a FACSCanto II flow cytometer instrument and analyzed using FACSDiva and FlowJo software (BD Biosciences). Ten thousand events were analyzed for each sample.

\section{Annexin V/7-AAD assay for apoptosis}

For Annexin V/7-AAD assays, cells were stained with Annexin V-FITC and 7-AAD, and evaluated for apoptosis by flow cytometry according to the manufacturer's protocol (BD PharMingen, San Diego, CA, USA). Briefly, $1 \times 10^{5}$ cells were washed twice with PBS, and stained with $5 \mu \mathrm{l}$ of Annexin V-FITC and $10 \mu \mathrm{l}$ of \&-AAD $(5 \mu \mathrm{g} / \mathrm{ml})$ in $1 \times$ binding buffer $(10 \mathrm{mM}$ HEPES, $\mathrm{pH} 7.4,140 \mathrm{mM} \mathrm{NaOH}$, $2.5 \mathrm{mM} \mathrm{CaCl}_{2}$ ) for $15 \mathrm{~min}$ at room temperature in the dark. The stained cells were acquired on a FACSCanto II flow cytometer instrument and analyzed using FACSDiva and FlowJo software (BD Biosciences). Ten thousand events were analyzed for each sample.

\section{Results}

\section{Pten ${ }^{398 A}$ accelerates MMTVneu-driven mammary tumorigenesis}

To study the in vivo function of PTEN phosphorylation by ATM, we engineered a knock-in allele in mice, in which serine at position 398 is substituted for alanine $\left(\right.$ Pten $^{398 A}$ ) (Supplementary Fig. 1A, details in materials and methods section). Pten ${ }^{398 A /+}$ and Pten ${ }^{398 A / 398 A}$ mice were viable, and their development was overtly normal. To investigate a possible role for ATM-dependent PTEN phosphorylation in breast 
cancer, we bred the Pten ${ }^{398 A}$ allele on the background of mice expressing the inactivated neu (Erbb2) fusion gene under the transcriptional control of the mouse mammary tumor virus (MMTV) promoter/enhancer [34] (MMTVneu, Supplementary Fig. 1B). In this well-established model, the MMTVneu transgene is expressed at low levels in normal mammary epithelium, leading to the development of tumors in the mammary glands with a reported median incidence of 205 days [34]. In our hands, Pten $^{+/+} ;$MMTVneu mice developed mammary tumors with the expected latency and displayed a median survival of 233 days (Fig. 1A). Comparatively, tumor development was accelerated in Pten $^{398 A / 398 A} ;$ MMTVneu mice, in which median survival was reduced to 199 days $(p<0.001$ by Mantel-Cox or Gehan-Breslow-Wilcoxon test) (Fig. 1A). Histological and immunohistochemical (IHC) analyses indicated that the tumors expressed strong levels of HER2, and exhibited the expected morphology and differentiation pattern [35] (Supplementary Fig. 2A, B).

Because ATM is an important protein for the control of the DDR, we hypothesized that accelerated tumorigenesis in Pten ${ }^{398 A / 398 A}$;MMTVneu mice could be associated with increased genomic instability. Phosphorylation of histone H2A variant $\mathrm{H} 2 \mathrm{AX}$ at Ser $139(\gamma \mathrm{H} 2 \mathrm{AX})$ can be used as a marker of DNA damage in cells [36]. Therefore, we examined $\gamma \mathrm{H} 2 \mathrm{AX}$ by IHC on paraffin-embedded tumor samples obtained from Pten $^{+/+} ;$MMTVneu and Pten ${ }^{398 A / 398 A} ;$ MMTVneu mice. $\gamma \mathrm{H} 2 \mathrm{AX}$ immunoreactivity was scored using a semiquantitative method (Table 1). Pten ${ }^{+/} ;$MMTVneu tumors generally showed little $\gamma \mathrm{H} 2 \mathrm{AX}$ expression (Fig. 1B). By contrast, all the Pten ${ }^{398 A / 398 A} ;$ MMTVneu samples analyzed were strongly positive for $\gamma \mathrm{H} 2 \mathrm{AX}$, suggesting higher levels of genomic instability (Fig. 1B, C). We confirmed these results by western blot analyses of tumor samples, which indicated that Pten $^{398 A / 398 A} ;$ MMTVneu tumors expressed higher levels of $\gamma \mathrm{H} 2 \mathrm{AX}$ than their Pten $^{+/+} ;$MMTVneu counterparts (Fig. 1D, E). We assessed the proliferation index of the tumors, by performing IHC for Ki-67, a marker widely used in routine pathology. No significant difference in Ki67 immunoreactivity was detected between tumors of the two genotypes $\mathrm{Pten}^{+/+}$; MMTVneu and Pten ${ }^{3984 / 398 A} ;$ MMTVneu (Supplementary Fig. 2C, D).

These results indicate that the Pten ${ }^{398 A}$ mutation accelerates MMTVNeu-driven tumorigenesis, and that this is associated with higher genomic instability but no evident alterations in cell proliferation.

\section{Blocking ATM-dependent PTEN phosphorylation causes genomic}

To mechanistically dissect how phosphorylation of PTEN by ATM regulates the DDR, we turned to more tractable cellular models. We generated MEFs from Pten ${ }^{398 A / 398 A}$ and
Pten $^{+/+}$littermates. Western blot analysis indicated that PTEN protein levels were not affected by the 398A mutation (Supplementary Fig. 3A, B). Furthermore, levels of phosphorylated AKT, a marker of PI3K pathway activity, were similar in Pten ${ }^{3984 / 398 A}$ and Pten $^{+/+}$MEFs (Supplementary Fig. 3B). We also generated a non-transformed human mammary epithelial cell line (MCF10A) [37] stably expressing wild-type PTEN (PTEN-WT), or the mutant form of PTEN that cannot be phosphorylated by ATM (PTEN-398A). In these cells, the endogenous PTEN gene has been deleted using CRISPR/Cas9 editing, creating PTEN null cells which were then reconstituted using stable transduction with either the wild type or the mutant form of the protein. The levels of PTEN protein and phosphorylated AKT were similar in MCF10A cells expressing PTEN-WT and PTEN-398A (Supplementary Fig. 3A), making these cells a suitable alternative model for the study of the molecular role of the phosphorylation of PTEN by ATM.

$\mathrm{Pten}^{+/+}$and Pten ${ }^{398 \mathrm{~A} / 398 \mathrm{~A}}$ MEFs were subjected to a dose of $10 \mathrm{~Gy}$ IR, and their proficiency in repairing the DNA damage was assessed by measuring the number of $\gamma \mathrm{H} 2 \mathrm{AX}$ and 53BP1foci per cell. In Pten ${ }^{+/+}$MEFs, we observed a peak in the number of foci per cells at $4 \mathrm{~h}$ after irradiation, returning near baseline levels by $24 \mathrm{~h}$ (Fig. 2A-C). Pten ${ }^{+/+}$ and Pten ${ }^{398 A / 398 A}$ accumulated similar numbers of foci per cell at $4 \mathrm{~h}$ post-IR. However, Pten ${ }^{398 A / 398 A}$ MEFs retained higher numbers of foci than their Pten $^{+/+}$counterparts at the $24 \mathrm{~h}$ time point, suggesting reduced DNA repair capability (Fig. 2A-C). Similar results were obtained when comparing MCF10A cells stably expressing PTEN-WT vs. PTEN398A (Supplementary Fig. 4A-C). To assess whether the impaired ability to resolve DNA damage foci in cells expressing PTEN-398A is due to defects in specific DNA repair pathways, we evaluated the efficiency of HR and non-homologous end-joining (NHEJ), using reporter assays. As previously reported [38], PTEN-WT expression enhanced the efficiency of both HR and NHEJ (Supplementary Fig. 4D, E). In MCF10A cells, PTEN-398A had similar effects to PTEN-WT in these experiments. These results indicate that the accumulation of DNA damage in cells expressing the mutated form of PTEN is not due to intrinsic defects in the DNA repair machinery (Supplementary Fig. 4D, E).

\section{PTEN-S398A mutation induces resistance to apoptosis}

To further understand how blocking ATM-dependent PTEN phosphorylation affects the cellular response to genotoxic insult, we evaluated the activity of stress response and apoptotic pathways in lysates from MCF10A cells expressing PTEN-WT or PTEN-398A, using an antibody array. As expected, cells expressing PTEN-WT promptly induced 
A

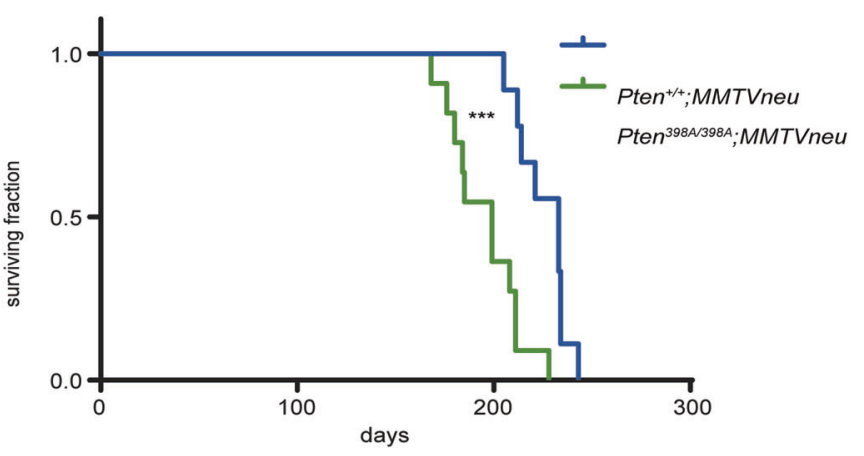

B

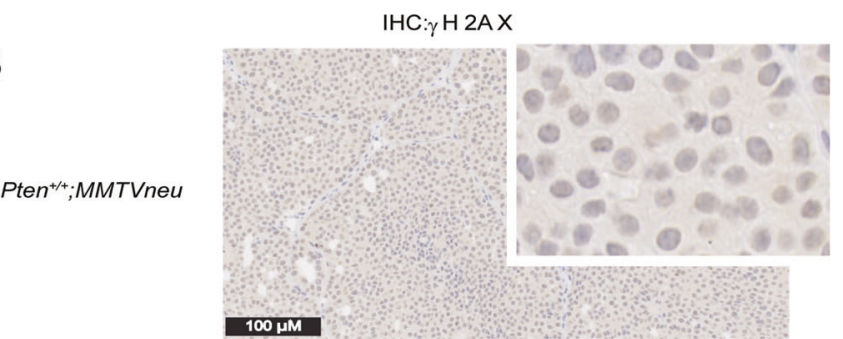

C

\begin{tabular}{|c|c|c|}
\hline & $\begin{array}{l}\text { Pten } \\
\text { MMTV́neu }\end{array}$ & $\begin{array}{l}\text { Pten }{ }^{398 \mathrm{~N} / 38 \mathrm{~A}} \mathrm{~A} \\
\text { MMTVneu }\end{array}$ \\
\hline Negative & 1 & 0 \\
\hline Weak positive & 3 & 0 \\
\hline Strong positive & 1 & 6 \\
\hline
\end{tabular}

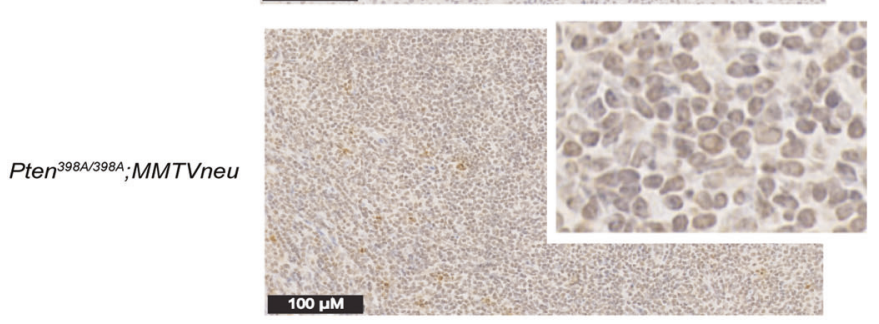

D
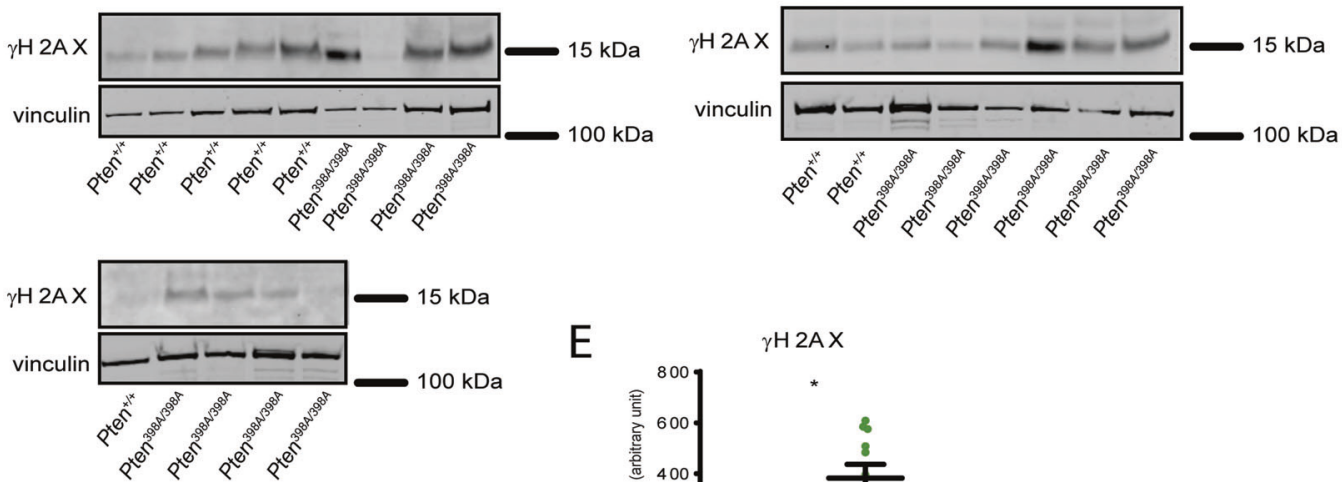

E

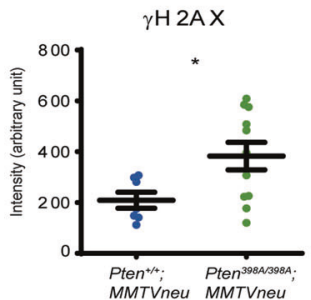

Fig. 1 Characterization of Pten ${ }^{3984 / 398 A} ; M M T V n e u$ knock-in mouse. A Survival rate in Pten $^{+/+} ;$MMTVneu and Pten ${ }^{398 A / 398 A}$; MMTVneu mice $(n=$ at least 10 mice/group). $(* * * p=0.0005$; Logrank test for comparisons of Kaplan-Meier survival curves). B Representative sections of Pten ${ }^{+/+} ;$MMTVneu and Pten ${ }^{398 A / 398 A}$; MMTVneu mammary tumors stained with a $\gamma \mathrm{H} 2 \mathrm{AX}$ antibody (magnification, $\times 10$; main image zoom, $\times 20$, insets zoom $\times 80$ ).

multiple stress response and apoptosis markers, as early as 30 min following genotoxic treatment (IR) (Supplementary Fig. 5A). In contrast, cells expressing PTEN-398A cells

C Semi-quantitatively expression scoring of Gamma-H2AX IHC stained tumors from Pten ${ }^{+/+} ;$MMTVneu and Pten ${ }^{398 A / 398 A} ;$ MMTVneu mice. D Immunoblot analysis of $\gamma \mathrm{H} 2 \mathrm{AX}$ in $\mathrm{Pten}^{+/+} ;$MMTVneu and Pten $^{398 A / 398 A}$;MMTVneu mammary tumor samples. Vinculin was used as a loading control. E Quantification of $\gamma \mathrm{H} 2 \mathrm{AX}$ levels, normalized to vinculin, from the blots shown in panel $(\mathbf{E})$ ( $t$ test, $* p=0.0332$ ).

showed a more modest induction of the same markers (Supplementary Fig. 5B), consistent with defective activation of the stress and apoptotic programs. 
Table. 1 Criteria for the semi-quantitative evaluation of $\gamma \mathrm{H} 2 \mathrm{AX}$ staining by immunohistochemistry on mouse mammary tumors.

\begin{tabular}{ll}
\hline Negative & Weak punctate staining encompassing $<50 \%$ of the nucleus of $<50 \%$ of neoplastic cells \\
Weak positive & Moderate to strong punctate staining encompassing $<50 \%$ of the nucleus of $50-75 \%$ of the neoplastic cells \\
Strong positive & Moderate to strong punctate staining encompassing up to $90 \%$ of the nucleus of $>75 \%$ of neoplastic cells \\
\hline
\end{tabular}
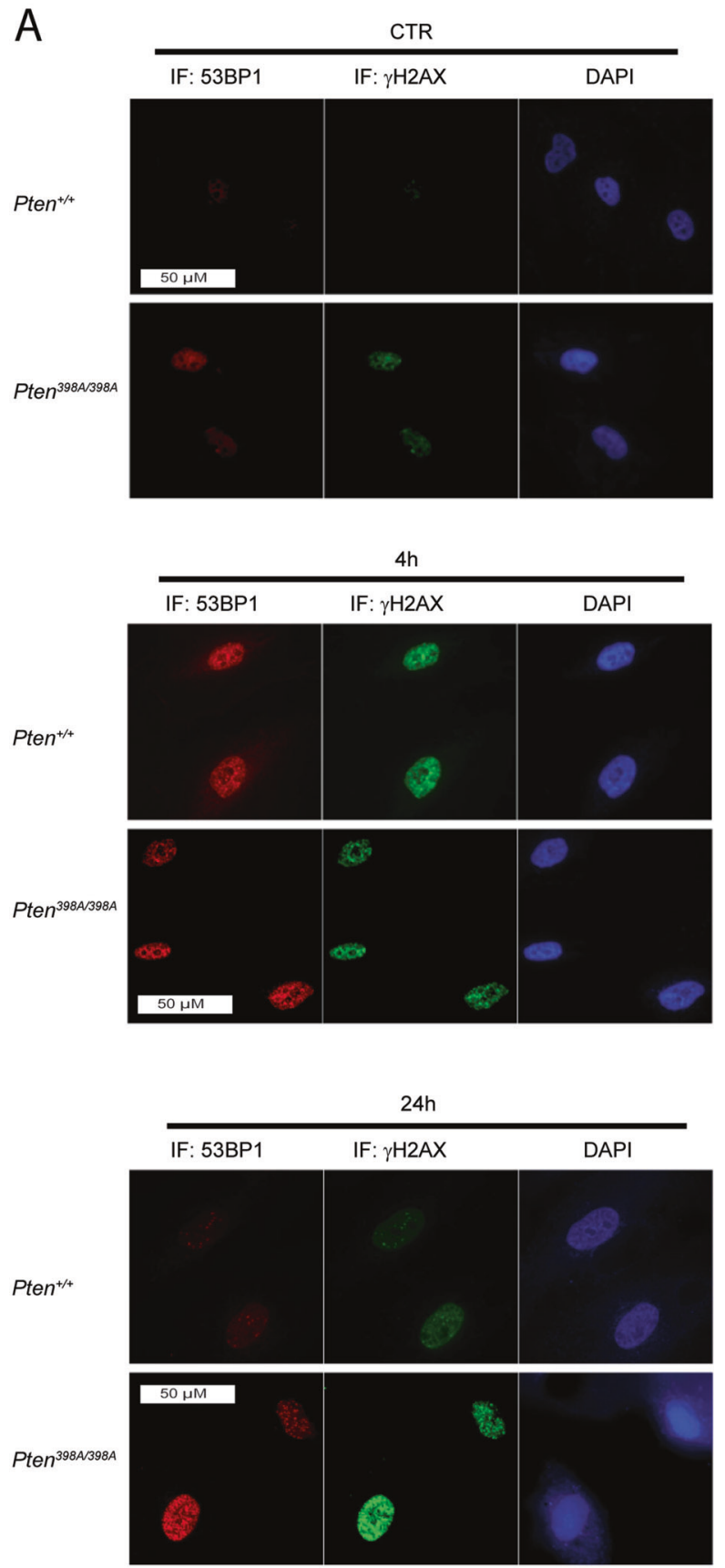

B

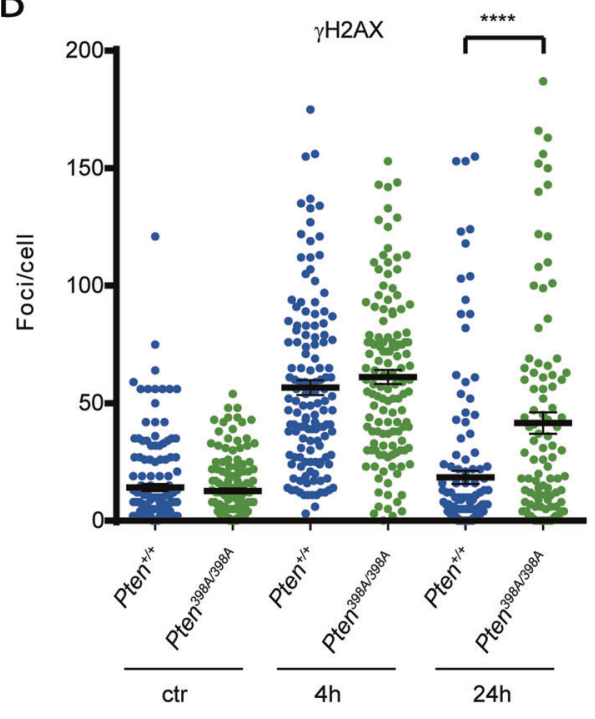

C

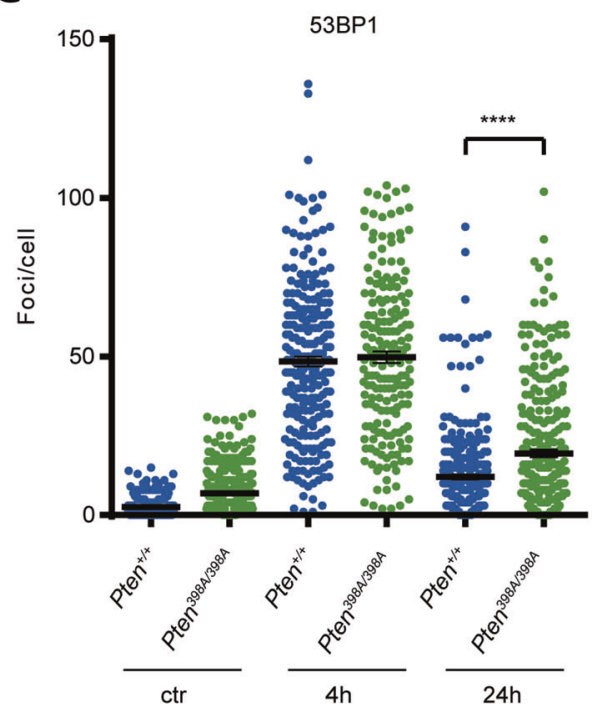

Fig. 2 Defective repair of DNA damage in cells expressing PTEN 398A. A Representative images of Pten $^{+/+}$and Pten ${ }^{398 A / 398 A}$ MEF cells exposed or not (CTR) to $10 \mathrm{~Gy}$ of ionizing radiation, fixed at the indicated times post-IR, and immunostained for $\gamma \mathrm{H} 2 \mathrm{AX}$, and 53BP1. DAPI was used to stain DNA. B Quantification of the number of $\gamma \mathrm{H} 2 \mathrm{AX}$ nuclear foci in MEF cells expressing PTEN WT or PTEN
398A. Nuclear foci in at least 100 nuclei were counted. ( $t$ test, $* * * *$ denotes $p<0.0001$. C Quantification of the number of 53BP1 nuclear foci in Pten $^{+/+}$and Pten ${ }^{398 A / 398 A}$ MEF cells. Mean and standard error of the mean are indicated for each transfection. Nuclear foci in at least 100 nuclei were counted. $* * * *$ denotes $p<0.0001$. 
A

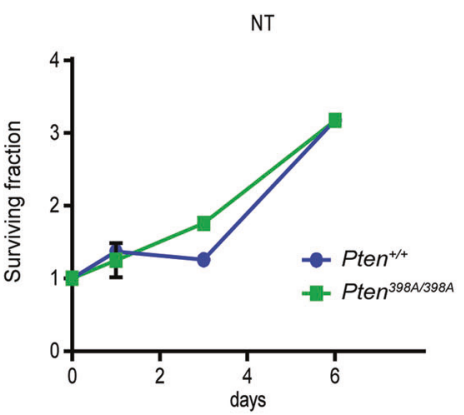

B

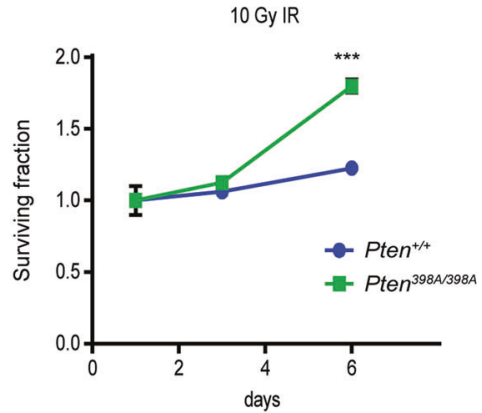

E

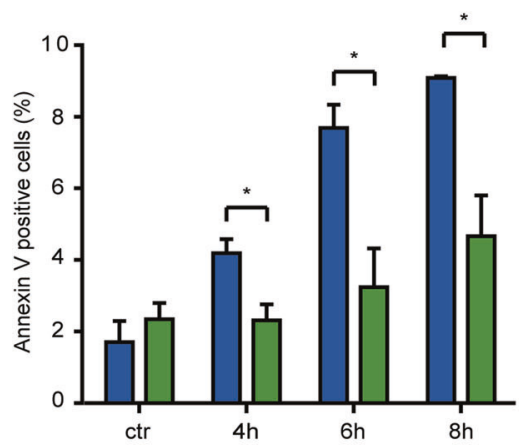

$\mathrm{F}$

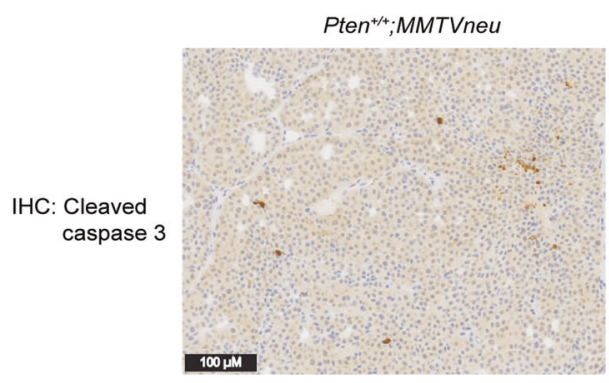

C

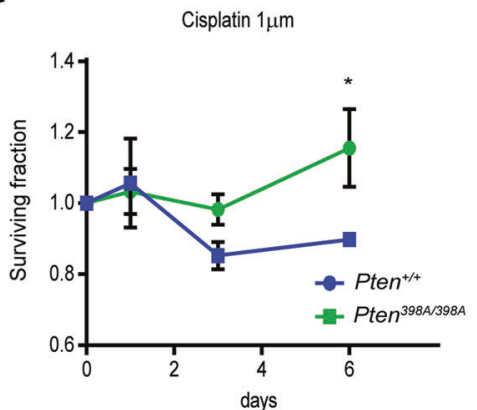

D

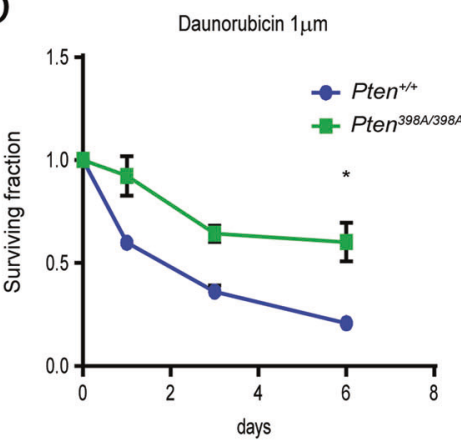

$\square \operatorname{Pten}^{+/+}$

$\square \operatorname{Pten}^{398 \mathrm{~A} 398 \mathrm{~A}}$

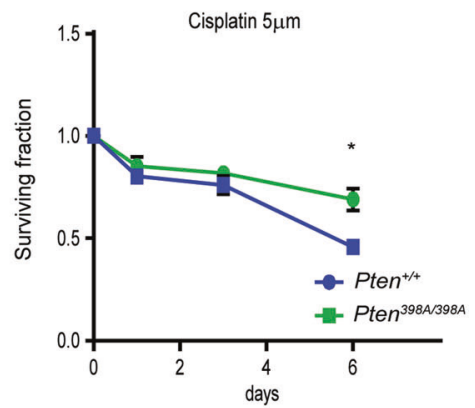

Daunorubicin $5 \mu \mathrm{m}$

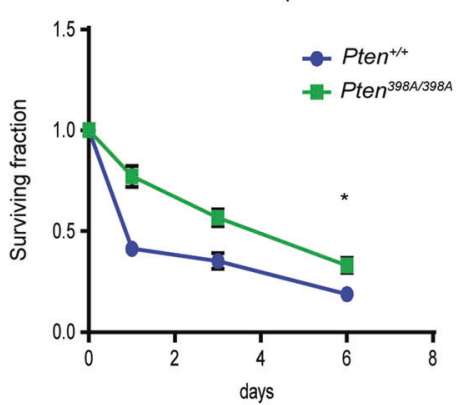

G

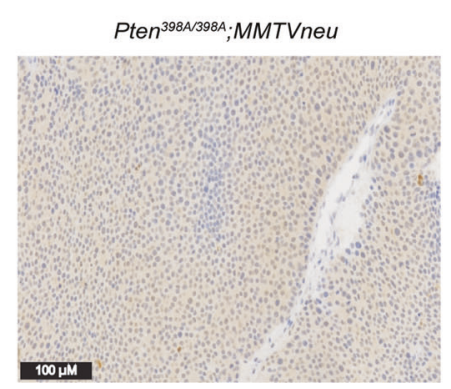

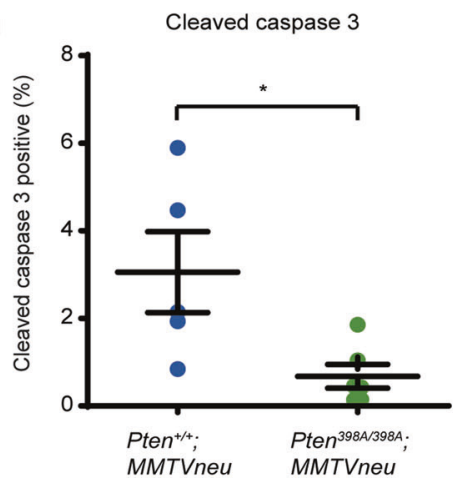

Fig. 3 Resistance to genotoxic stress and defective activation of apoptosis induced by expression of PTEN 398A. A-D Surviving fraction of Pten $^{+/+}$and Pten ${ }^{398 A / 398 A}$ MEFs, recorded over 6 days, in untreated cells (A) or following exposure to $5 \mathrm{~Gy}$ of ionizing radiation (B), 1 and $5 \mu \mathrm{m}$ Cisplatin (C) and 1 and $5 \mu \mathrm{M}$ Daunorubicin (D). All data are expressed as mean $\pm \mathrm{SD}$. Experiments in triplicate. $t$ test, ${ }^{*} p<$ 0.05. E Quantification of annexin-V/FITC positive Pten ${ }^{+/+}$and Pten $^{398 A / 398 A}$ MEF cells after treatment with $10 \mathrm{~Gy}$ of ionizing radiation. Cells were collected at the indicated time points after treatment, stained and analyzed by flow cytometry. Data are expressed as mean \pm SD. $* p<0.05$ compared with corresponding controls $(n=$ 3). F Immunohistochemical staining of cleaved cleaved caspase 3 in Pten $^{+/+} ;$MMTVneu and Pten ${ }^{398 A / 398 A} ;$ MMTVneu mammary tumor samples. G Quantification of cleaved cleaved caspase 3 positive cells in tumor sections from Pten ${ }^{+/+} ;$MMTVneu and Pten ${ }^{398 A / 398 A}$; MMTVneu mammary tumors ( $t$ test, $\left.{ }^{*} p=0.0402\right)$. 
We reasoned that increased genomic instability, coupled with the defective activation of the stress response and apoptotic pathways, in cells expressing the mutant form of PTEN should lead to phenotypic differences in response to DNA damaging agents. We therefore assessed the resistance of cells expressing wild-type or mutant PTEN to genotoxic stress. There was no difference in the growing rate of Pten ${ }^{+/+}$and Pten ${ }^{398 A / 398 A}$ MEF cultures, or of MCF10A cells expressing PTEN-WT vs. PTEN-398A, under normal culture conditions (Fig. 3A and Supplementary Fig. 5C). The cells were then subjected to different genotoxic stress treatments: IR, cisplatin, and daunorubicin. In all the conditions, Pten ${ }^{398 A / 398 A}$ MEFs and PTEN-398Aexpressing MCF10A cells were more resistant to genotoxic stress than their respective counterparts expressing wildtype PTEN (Fig. 3B-D and Supplementary Fig. 5D, E). Consistent with this phenotype, apoptosis induction by IR was lower in MCF10A cells expressing PTEN-398A vs. PTEN-WT, as judged by Annexin V staining using flow cytometry (Fig. 3E).

We confirmed these observations in our in vivo model by performing immunohistochemistry staining with caspase-3 antibody, a widely used marker for detecting apoptotic cells, on Pten ${ }^{+/+} ;$MMTVneu and Pten ${ }^{398 A / 398 A} ;$ MMTVneu tumors. Indeed, MMTVneu tumors harbored fewer caspase-3-positive cells when compared to their corresponding $\mathrm{Pten}^{+/+}$; MMTVneu, Pten ${ }^{398 A / 398 A}$ (Fig. 3F, G). Altogether, these results suggest that cells in which PTEN cannot be phosphorylated by ATM are resistant to the induction of apoptosis following genotoxic stress. To assess whether the persistence of cells expressing PTEN-398A with unresolved DNA damage following irradiation (Fig. 2B, C and Supplementary Fig. 4B, C) is a consequence of the failure to induce the apoptotic response, we pretreated cells with z-VAD-FMK (zVAD), a pan-caspase inhibitor, prior to IR. $z V A D$ increased the number of unresolved DNA damage foci in PTEN-WT cells-compared to that of DMSO treatment-to a level comparable to that observed in vehicle (DMSO)-treated PTEN-398A cells (Supplementary Fig. 5F). However, it has to be noted that zVAD pretreatment also slightly increased the number of unresolved DNA damage foci in PTEN-398A cells following IR.

\section{Impaired G1/S cell cycle checkpoint in cells deficient for ATM-dependent PTEN phosphorylation}

To complement the above studies, we performed cDNA microarray analyses on MCF10A cells expressing either PTEN-WT or PTEN-398A, and treated with cisplatin to induce genotoxic stress. The list of differentially expressed genes was analyzed by Gene Set Enrichment Analysis [39]. Interestingly, genes upregulated in cells expressing PTEN$398 \mathrm{~A}$ were related to the activation of the G1/S checkpoint, such as G1/S phase-specific transcription, E2F targets and cell cycle regulatory genes controlled by the Rb1 pathway (Supplementary Fig. 6A).

Based on the above observations, we speculated that the resistance of cells expressing PTEN-398A to genotoxic stress may be due to failure to arrest the cell cycle in response to DNA damage. To test this possibility, we measured the ability of synchronized cells expressing wildtype or mutant PTEN to undergo cell cycle arrest at the G1/ $\mathrm{S}$ checkpoint, in response to DNA damage. No noticeable difference in the proportion of cells in G1, S, and G2/M phases was observed in normally cycling cells expressing PTEN-WT or PTEN-398A (Fig. 4A). To synchronize the cells at the G1/S checkpoint, we subjected them to a double thymidine pulse. This treatment effectively arrested both PTEN-WT and PTEN-398A cells at the G1/S boundary (Fig. 4B). The cells were then released in normal growth media, treated with IR during $\mathrm{S}$ phase progression, and collected $6 \mathrm{~h}$ later for cell cycle distribution analysis by flow cytometry (following an experimental scheme illustrated in Supplementary Fig. 7A). While most of the PTEN-WT cells were arrested in S-phase, PTEN-398A cells failed to arrest the cell cycle, having instead progressed through the G2/M phase (Fig. 4C). This observation was confirmed by measuring the proportion of cells expressing Phospho-Histone H3 (Ser10), which marks cells in the mitotic phase. (Fig. 4D). There was no difference in cell cycle progression in non-irradiated cells expressing PTEN-WT vs. PTEN398A following release from the double thymidine block (Supplementary Fig. 7B).

At the G1/S-phase checkpoint, CDK2 becomes hypophosphorylated [40]. Accordingly, cells expressing PTENWT, that were arrested in $\mathrm{S}$ phase following release from double thymidine block and irradiation, exhibited low levels of CDK2 phosphorylation (Fig. 5A). Conversely, PTEN-398A cells subjected to the same treatment had higher levels of phosphorylated CDK2 (Fig. 5A), consistent with defective activation of the DNA damage checkpoint.

p2 $7^{\mathrm{Kip} 1}$, a Cip/Kip member, is a CDK inhibitor that causes G1/S arrest by inhibiting the activity of the CDK2Cyclin E complex [41]. Phosphorylation of $\mathrm{p} 27^{\mathrm{Kip} 1}$ by AKT reduces its inhibitory activity towards CDK2-Cyclin E complex and promotes cell cycle progression [42, 43]. Following the above protocol to synchronize and release cells in G1/S (Supplementary Fig. 7A), we evaluated the activation of the AKT/p2 $7^{\text {Kip1 }}$ axis $2 \mathrm{~h}$ after IR. At that time point, levels of phosphorylated AKT and phosphorylated p2 $7^{\text {Kip1 }}$ were higher in cells expressing PTEN-398 compared to their PTEN-WT counterparts (Fig. 5B). Given that p2 $7^{\mathrm{Kip} 1}$ binds CDK2/Cyclin $\mathrm{E}$ to inhibit cell cycle progression, we sought to determine the composition of this complex under our experimental conditions. We 
A
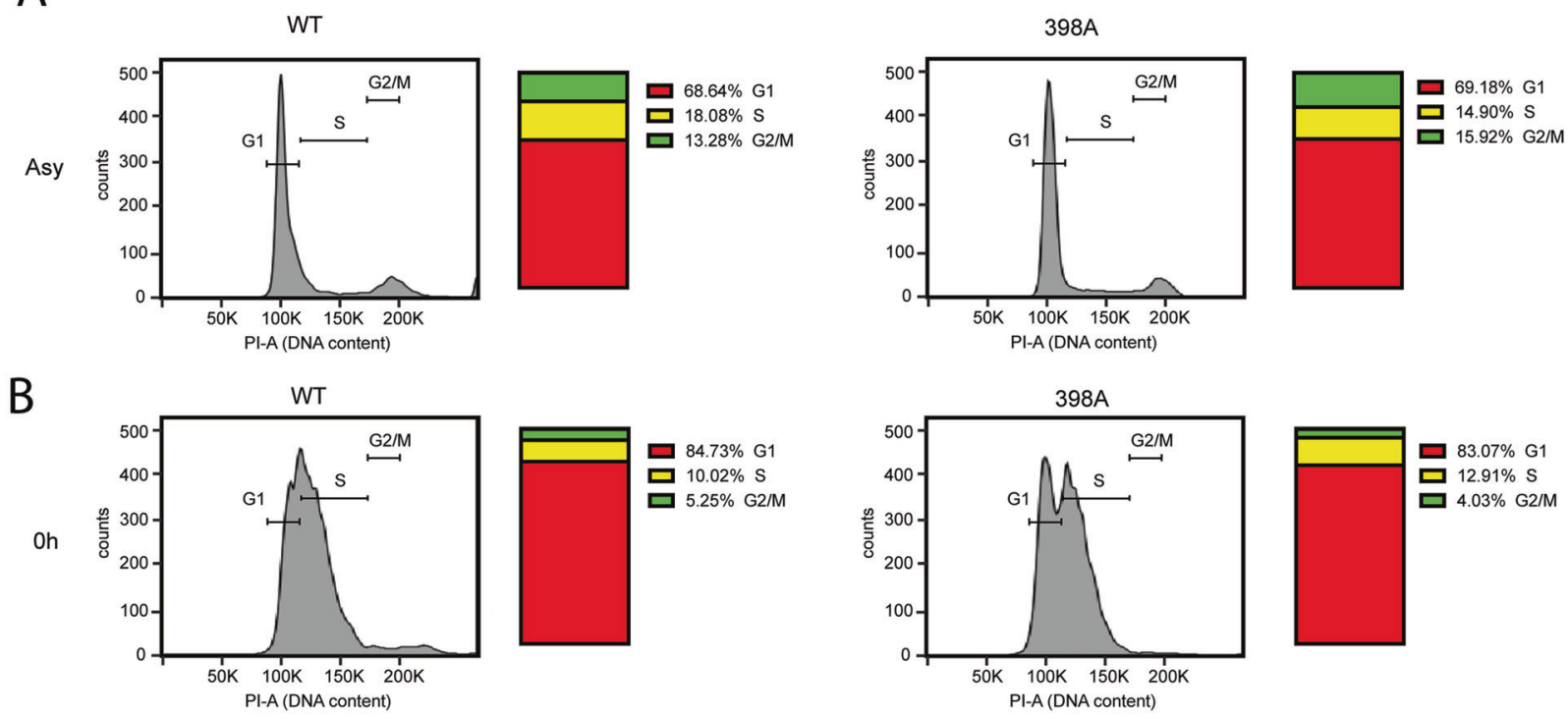

C
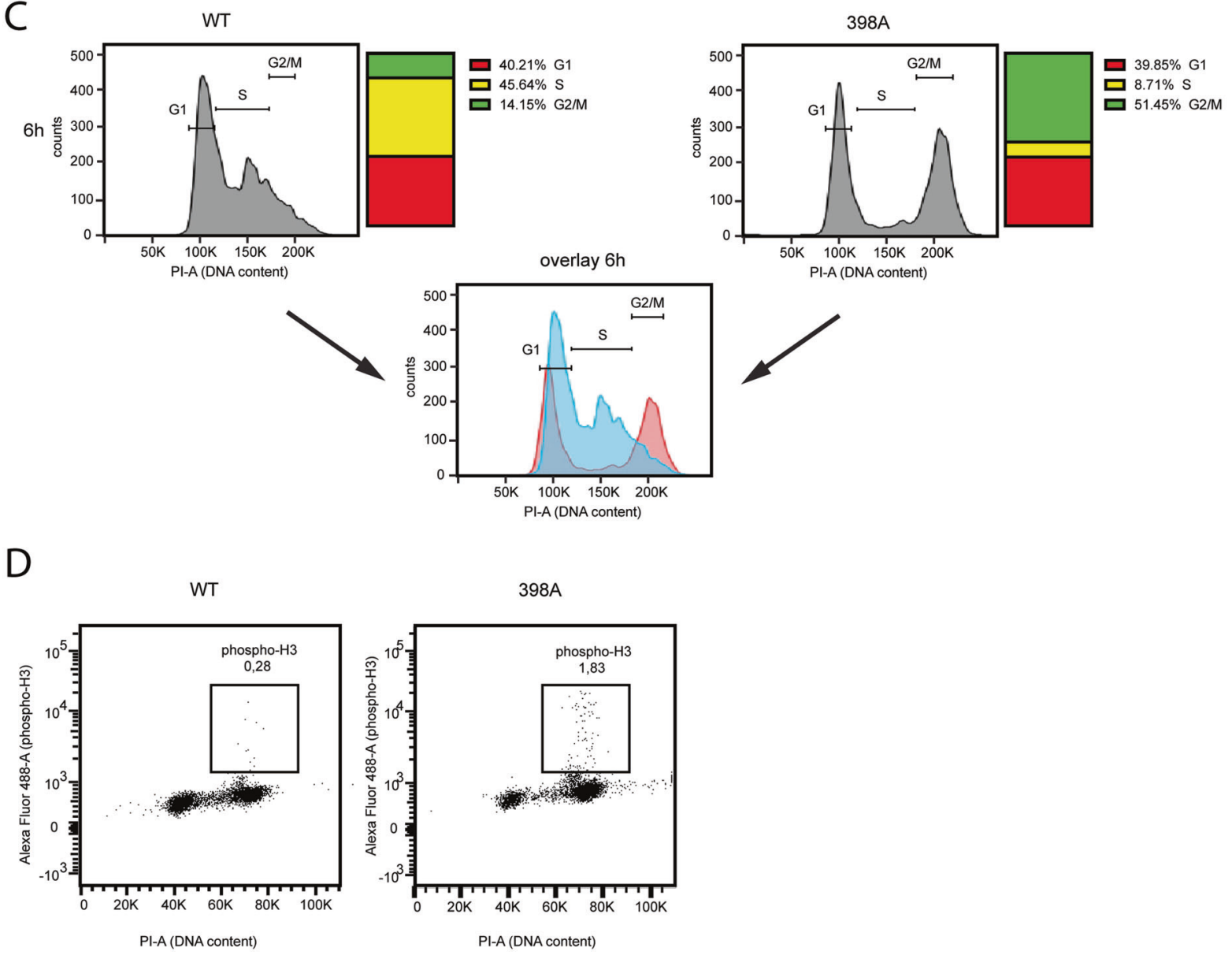

Fig. 4 Altered cell cycle progression following DNA damage exposure in cells expressing PTEN 398A. A-C Cell cycle profiles, assessed by flow cytometry, of MCF10A cells expressing PTEN-WT or PTEN-398A. Cells were either untreated or treated with IR (5 Gy). The captions (and corresponding quantification on the right) correspond to asynchronous cells (asy, A), cells arrested by double thymidine block $(0 \mathrm{~h}, \mathbf{B})$ and cells synchronized by double thymidine

block, released in full media, treated with IR and collected after $6 \mathrm{~h}$ (C). The experiment was repeated 3 times; a representative example is shown. D Phospho-H3 and DNA content, assessed by flow cytometry, in MCF10A cells expressing PTEN-WT or PTEN-398A that were synchronized by double thymidine block, released in full media, treated with IR and collected after $6 \mathrm{~h}$. The figure is representative of three different experiments. 
A

B
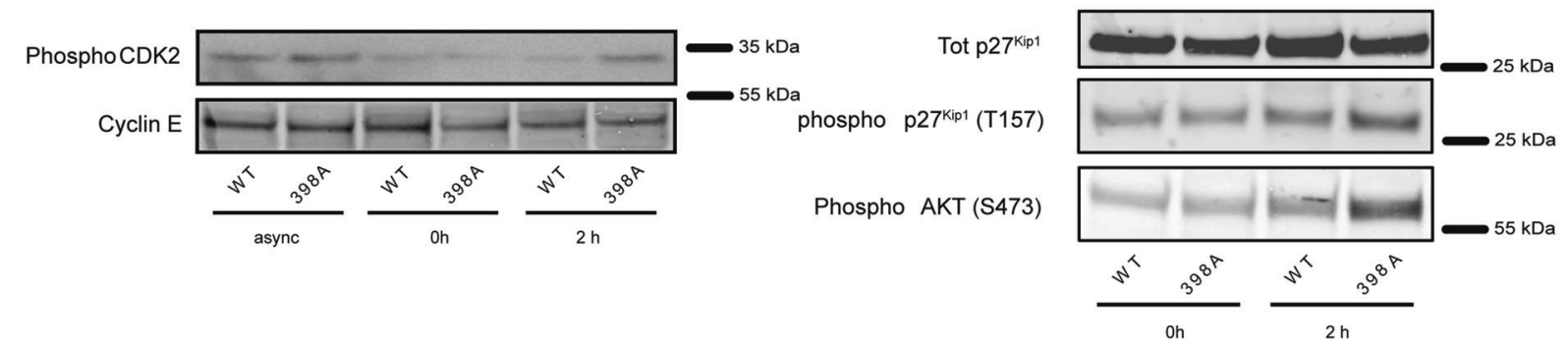

C
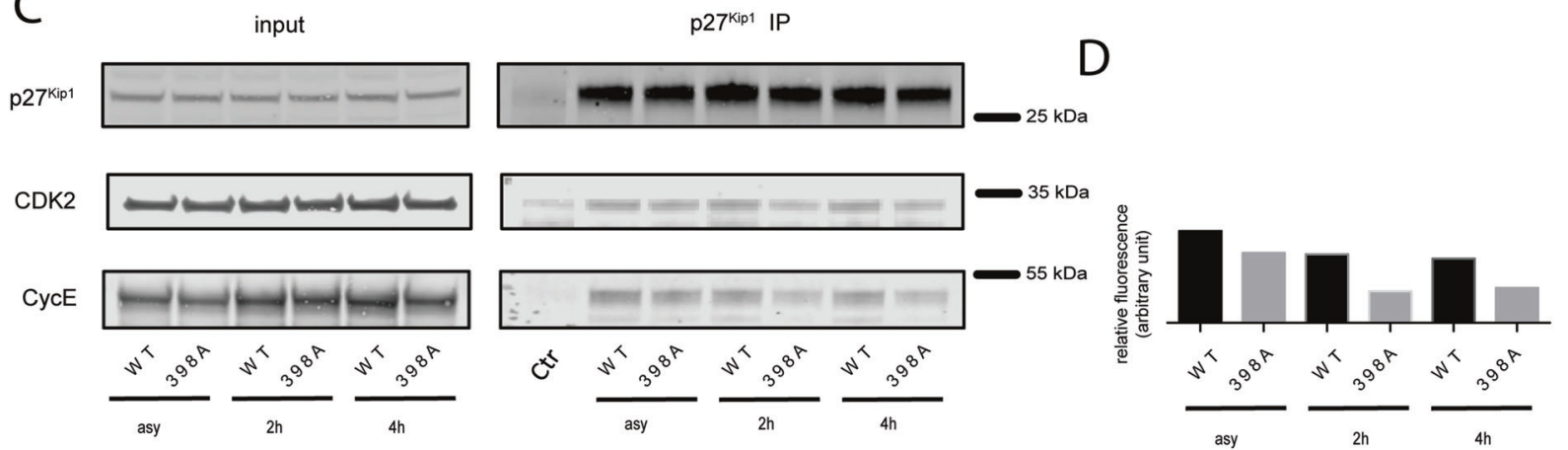

$E$

$\mathrm{F}$

Phospho AKT (S473)

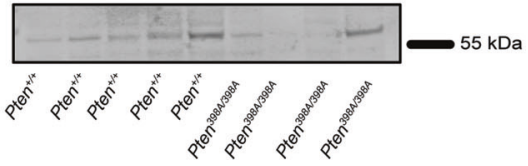

phospho p27 $7^{\text {kip1 }}$ (T157)

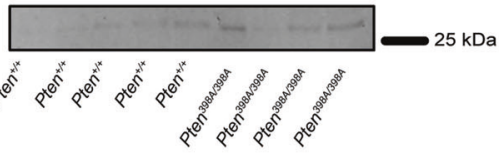

Phospho AKT (S473)

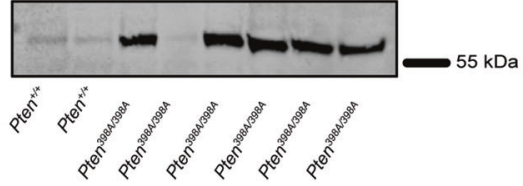

phospho p27 ${ }^{\text {Kip1 }}($ T157)

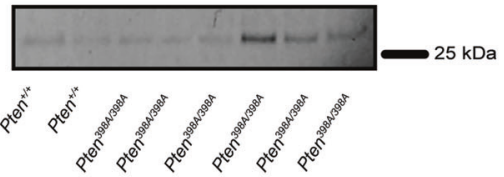

Phospho AKT (S473)

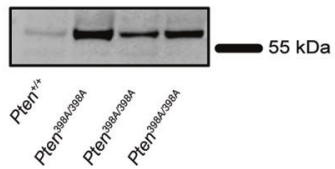

phospho p2 $7^{\text {kip1 } 1}(\mathrm{~T} 157)$

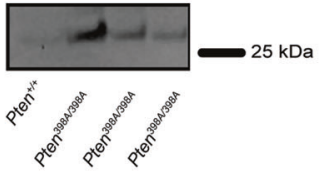

G

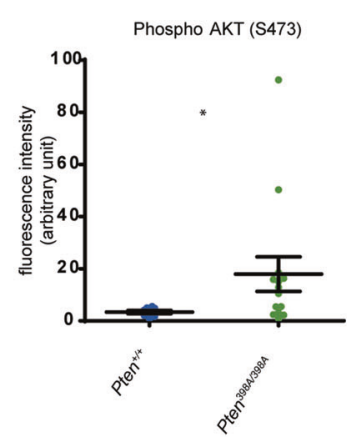

$\mathrm{H}$

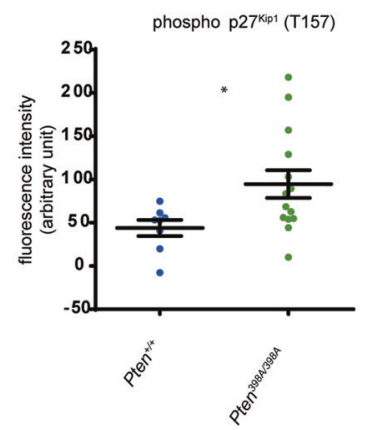

immunoprecipitated endogenous $\mathrm{p} 27^{\mathrm{Kip} 1}$ from cells expressing PTEN-WT and PTEN-398A, and immunoblotted for CDK2 and Cyclin E. While p2 $7^{\text {Kip1 }}$ effectively co-immunoprecipitated with CDK2 and Cyclin E in irradiated PTEN-WT cells, these interactions were diminished in PTEN-398A cells (Fig. 5C, D). 
Fig. 5 Cells expressing PTEN 398A display defective activation of the G1/S checkpoint. A Levels of phosho-CDK2 and CycE in lysate prepared from MCF10A cells expressing PTEN-WT or PTEN-398A, either grown asynchronously (asy), arrested by double thymidine block $(0 \mathrm{~h})$ or synchronized by double thymidine block, released in full media, treated with IR and collected after $6 \mathrm{~h}$. B Levels of p27 ${ }^{\mathrm{Kip} 1}$, phospho-T157 p27 $7^{\text {Kip1 }}$, or phosho-S473 AKT in lysates prepared from MCF10A cells expressing PTEN-WT or PTEN-398A. Cells were either arrested by double thymidine block $(0 \mathrm{~h})$ or synchronized by double thymidine block, released in full media, treated with IR and collected after $2 \mathrm{~h}$. C Levels of p27 $7^{\mathrm{Kip} 1}, \mathrm{CDK} 2$, or CycE in total cell lysates (input), or in $\mathrm{p} 27^{\mathrm{Kip} 1}$ immunoprecipitates (p27 IP) from MCF10A cells expressing PTEN-WT or PTEN-398A. Cells were either grown asynchronously (asy) or synchronized by double thymidine block, released in full media, treated with IR and collected after 2 or 4 h. D Quantification of CDK2 binding to p $27^{\text {Kip } 1}$ from the immunoprecipitation experiment shown in panel $(\mathbf{G})$. Values (in arbitrary unit) are expressed as signal of co-immunoprecipitated CDK2 relative to the signal of immunoprecipitated $\mathrm{p} 27^{\mathrm{Kip} 1}$. E Immunoblot analysis of phospho-AKT in Pten ${ }^{+/+} ;$MMTVneu and Pten ${ }^{398 A / 398 A}$; MMTVneu mammary tumor samples. Vinculin (shown in Fig. 1D) was used as a loading control. F Immunoblot analysis of phospho-p $27^{\text {Kip1 }}$ in Pten $^{+/+} ;$MMTVneu and Pten ${ }^{398 A / 398 A} ;$ MMTVneu mammary tumor samples. Vinculin (shown in Fig. 1D) was used as a loading control. G Quantification of phospho-AKT (S473) levels, shown in panel (E), normalized to vinculin, shown in Fig. 1D. D Quantification of phospho-p27 ${ }^{\text {Kip1 }}$ (T157) levels, shown in panel (F), normalized to vinculin, shown in Fig. 1D.

To verify the relevance of our findings in the context of MMTVNeu model, we evaluated the activation of the AKTp27 $7^{\text {Kip } 1}$ axis in Pten $^{+/+} ; M M T V N e u$ and PTEN ${ }^{398 A / 398 A}$; MMTVNeu mammary tumors. Consistently with what we observed in MCF10A cells, immunoblotting analyses revealed higher levels of phosphorylated AKT and phosphorylated $\mathrm{p} 27^{\mathrm{Kip} 1}$ in lysates from $P T E N^{398 A / 398 A}$; MMTVNeu tumors compared with their $\mathrm{Pten}^{+/+} ; \mathrm{MMTVNeu}$ counterparts (Fig. 5E-H). This observation is of particular importance as it establishes a direct causal link between the molecular effects elicited by PTEN-398 mutation and the in vivo mammary tumor phenotype.

Altogether, our results indicate that preventing phosphorylation of PTEN by ATM increases AKT and p27 $7^{\text {Kip1 }}$ activation following DNA damage, in turn favoring the activity of the CDK2/Cyclin E complex, and driving cell cycle progression.

\section{Blocking ATM-dependent phosphorylation impairs subcellular redistribution of PTEN following DNA damage}

Given that mutation of the ATM phosphorylation site on PTEN does not appear to intrinsically affect PTEN lipid phosphatase activity under physiological conditions (Supplementary Fig. 3B), we next sought to explain why phosphorylation of AKT was enhanced following DNA damage in cells expressing PTEN-398A. Since PTEN functions at the plasma membrane to dephosphorylate phosphatidyl-inositol 3, 4, 5 phosphate $\left(\mathrm{PIP}_{3}\right)$, we investigated its cellular localization upon DNA damage. MCF10A cells were synchronized and irradiated as described above, and the subcellular distribution of PTEN was analyzed by immunofluorescence. The PTEN-WT and PTEN-398A proteins were similarly localized at steady state in the nucleus and at the plasma membrane (Fig. 6A, B). Following IR treatment, PTEN-WT accumulated at the plasma membrane (Fig. 6A, B). By contrast, no relocalization of PTEN-398A was detected in these conditions (Fig. 6A, B). We further confirmed these results by cellular fractionation and immunoblot analysis of membrane-associated PTEN (Fig. 6C, D). These results suggest that phosphorylation of PTEN by ATM causes PTEN redistribution at the plasma membrane, which is associated with reduced AKT pathway activation.

\section{Discussion}

Early studies in the PI3K field considered PTEN to be a ubiquitously expressed phosphatase functioning as a negative regulator of the kinase pathway, rather than a dynamic signaling molecule. Subsequent studies challenged this initial belief, revealing that PTEN activity is subject to extensive regulation mainly by post-translational modification. We previously identified how sumoylation of PTEN at position 254 controls its nuclear localization and function. We also observed that sumoylation of PTEN is mutually exclusive with its phosphorylation by ATM at position 398 [27]; however, the physiological implications of this regulation event were unknown. In the present work, we uncovered a novel mechanism whereby the kinase ATM affects the subcellular distribution of PTEN, in turn controlling the activity of the PI3K pathway in the context of the DNA damage checkpoint. It is currently unclear how this regulation is implemented at the molecular level. The phosphorylation of PTEN at position 398 could alter its interaction with proteins that control its localization whithin the cell. Alternatively, the addition of a phosphate group could induce conformational changes to PTEN protein and alter its ability to interact with the lipid membrane as it has been proposed by several structural biochemistry studies $[44,45]$.

We studied the effect of the Pten ${ }^{398 A}$ mutation on mammary tumors driven by the HER2/neu oncogene in MMTVNeu transgenic mice. This model has been shown to recapitulate the gene expression profile of human luminal B breast cancers, and has been used to test clinically relevant therapies and identify potential biomarkers of drug sensitivity and resistance [46]. The acceleration in the tumorigenesis process we observed in MMTVneu; Pten $^{398 A / 398 A}$ mice compared to $\mathrm{Pten}^{+/+} ; \mathrm{MMTVneu}$ littermates is 
A
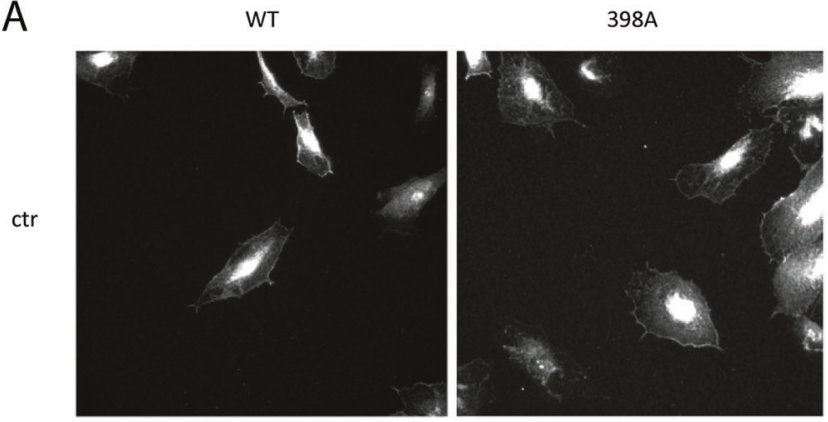

IR
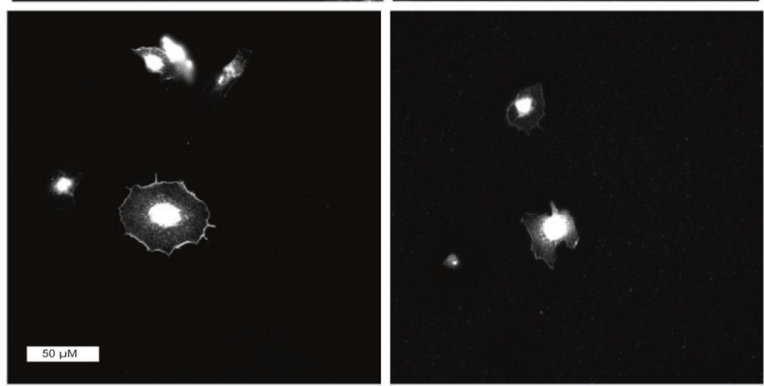

B

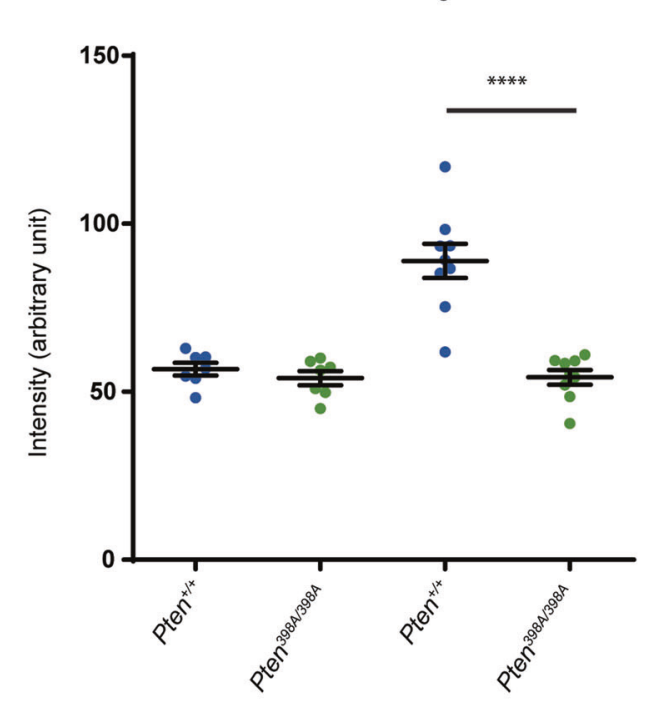

C

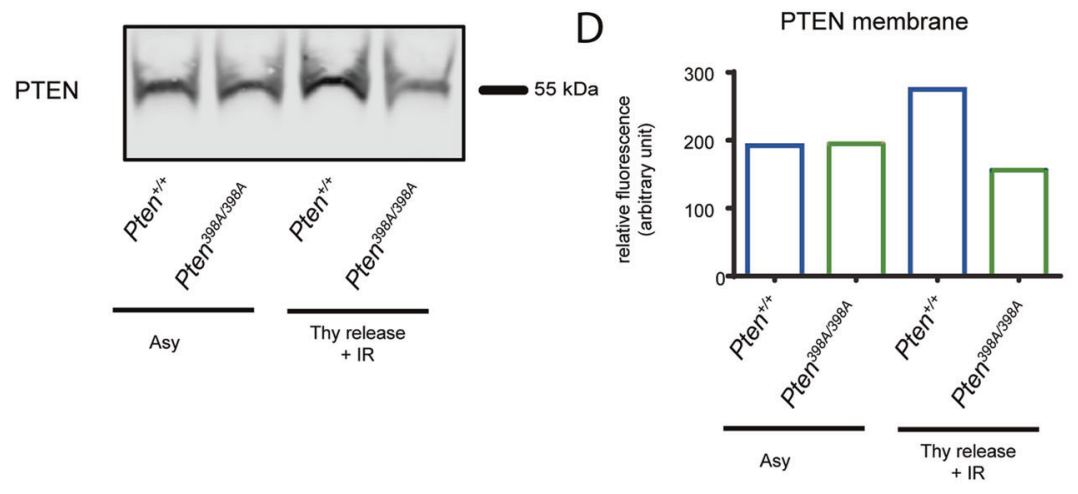

E

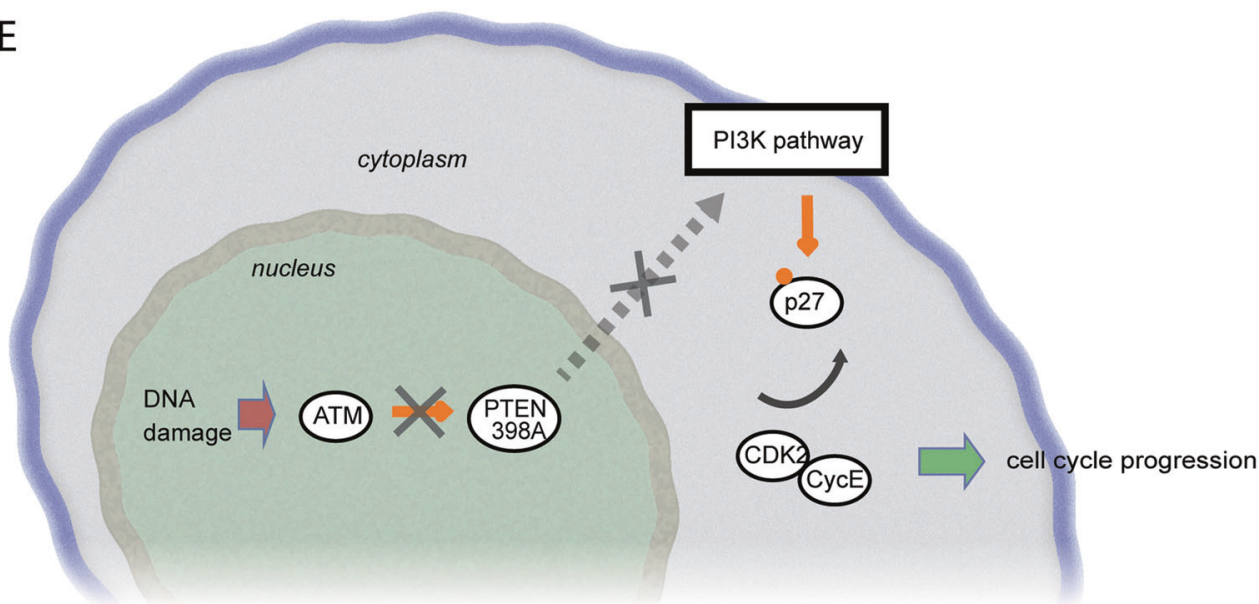

Fig. 6 Phosphorylation by ATM of PTEN in position 398 mediates its relocalization to the membrane. A Representative images of Pten $^{+/+}$and Pten ${ }^{398 A / 398 A}$ MEFs cells exposed or not (CTR) to $10 \mathrm{~Gy}$ of ionizing radiation, fixed at the indicated times post-IR, and immunostained for PTEN. B Quantification of membrane-associated PTEN fluorescent signal, relative to the total membrane area of the cell $(t$ test, $* * * * p<0.0001)$. C Immunoblot analysis of membrane-associated PTEN in Pten $^{+/+}$and Pten ${ }^{398 A / 398 A}$ MEFs cells, exposed or not (CTR) to $10 \mathrm{~Gy}$ of ionizing radiation. D Quantification of immunoblot data shown in panel (G). E Model of the effect of phosphorylation of PTEN by ATM on PTEN subcellular localization, PI3K pathway activity, and CDK2/ CycE-dependent cell cycle checkpoint regulation, in response to DNA damage. 
characterized by a decrease in apoptosis, and an increase in genome instability, which can be attributed to a defective activation of the DDR checkpoint. Interestingly, previous studies showed that the MMTVneu model is particularly susceptible to additional mutations in DDR regulators, as is the case in bi-transgenic mice expressing the HER2 oncogene and an inactivated form of $p 53$ (WAP-p53-172H) with a tumor latency shortened to 154 days (compared to 205 days of the MMTVneu) [47].

By using two different cell systems, we were able to dissect the molecular mechanism responsible for the in vivo phenotype and reveal a novel regulatory function of ATM, one of the main tumor suppressors in cells. p2 $7^{\mathrm{Kip} 1}$ negatively regulates the G1-S phase progression by binding to and inhibiting cyclin dependent kinases (CDKs), and low levels of $\mathrm{p} 27^{\mathrm{Kip} 1}$ correlate with poor prognosis and survival in many types of cancers [48]. However, in human cancers, genetic alterations of $\mathrm{p} 27^{\mathrm{Kip} 1}$ are rare. Rather, $\mathrm{p} 27^{\mathrm{Kip} 1}$ is misregulated in tumors by transcriptional and posttranscriptional mechanisms. Based on our results, we suggest a model whereby expression of a PTEN form which is resistant to the kinase activity of ATM leads to an impairment of the ability of $27^{\mathrm{Kip} 1}$ to bind the CDK2/CycE complex and properly arrest the progression of the cell cycle following genotoxic stress (Fig. 6E). Our data are in accordance with several studies that have shown how the functional impairment of $\mathrm{p} 27^{\mathrm{Kip} 1}$ plays a prominent role in breast cancers. Specifically, mislocalization of $\mathrm{p} 27^{\text {Kip } 1}$, which is regulated by phosphorylation events [49], in HER2 positive breast cancer cells confers resistance to anti-HER2 targeted therapy [50].

Cell cycle checkpoints play a pivotal role in the control of genetic stability, and their disruption is closely associated with malignant transformation [51]. DNA repair mechanisms ensure the maintenance of genomic integrity over a cell's lifespan. DNA damage checkpoints, on the other hand, are responsible for determining the fate of genomically unstable cells by activating cell cycle arrest and, ultimately, apoptosis. Disruption of these molecular processes in cells not only increases their likelyhood of neoplastic transformation, but also has therapeutic implications. DNA damage checkpoints directly affect the sensitivity of cells to damage during chemo- or radiotherapy. Therefore, assessing the integrity of checkpoints in cancerous lesions may assist in the design of better therapeutic strategies. This can include the specific targeting of checkpoint components that are defective in certain cancer cells, in order to enhance the antitumor effect of chemotherapies by restoring the sensitivity to cell-cycle arrest and apoptotic cell death. By unveiling a novel mechanism connecting the DDR, cell cycle checkpoints, and PTEN, a key tumor suppressor that is often disrupted in cancers, our study has therapeutic implications for the clinical development of a number of new anticancer drugs that target various cell cycle regulators.

Acknowledgements We thank Dr. Miguel A. Pujana for advice on the analysis of gene expression patterns and Dr. Jessica A. Downs for critical reading of the paper.

Funding statement This study was supported by a grant from Canadian Institutes of Health Research (CIHR) Foundation Grant to T.W. M. C.B. was supported by a Cancer Research Institute Irvington Postdoctoral Fellowship.

Author contributions $\mathrm{CB}$ and $\mathrm{TM}$ designed the research, $\mathrm{CB}, \mathrm{JF}, \mathrm{BS}$, AW, JH, AYT, EC, LB, and CG performed research, CB, JF, and TM analyzed data, $\mathrm{CG}, \mathrm{VS}$, and $\mathrm{TM}$ supervised research and $\mathrm{CB}, \mathrm{JF}$, and TM wrote the paper.

\section{Compliance with ethical standards}

Conflict of interest The authors declare no competing interests.

Ethic statement Our studies did not include human participants, human data or human tissue. For the animal studies, a protocol detailing experimental procedures following the Canadian Council on Animal Care guidelines was submitted to-and approved by-the animal studies committee at Ontario Cancer Institute.

Publisher's note Springer Nature remains neutral with regard to jurisdictional claims in published maps and institutional affiliations.

Open Access This article is licensed under a Creative Commons Attribution 4.0 International License, which permits use, sharing, adaptation, distribution and reproduction in any medium or format, as long as you give appropriate credit to the original author(s) and the source, provide a link to the Creative Commons license, and indicate if changes were made. The images or other third party material in this article are included in the article's Creative Commons license, unless indicated otherwise in a credit line to the material. If material is not included in the article's Creative Commons license and your intended use is not permitted by statutory regulation or exceeds the permitted use, you will need to obtain permission directly from the copyright holder. To view a copy of this license, visit http://creativecommons. org/licenses/by/4.0/.

\section{References}

1. Maehama T, Dixon JE. The tumor suppressor, PTEN/MMAC1, dephosphorylates the lipid second messenger, phosphatidylinositol 3,4,5-trisphosphate. The. J Biol Chem. 1998;273:13375-8.

2. Stambolic V, Suzuki A, de la Pompa JL, Brothers GM, Mirtsos C, Sasaki T, et al. Negative regulation of PKB/Akt-dependent cell survival by the tumor suppressor PTEN. Cell 1998;95:29-39.

3. Chalhoub N, Baker SJ. PTEN and the PI3-kinase pathway in cancer. Annu Rev Pathol. 2009;4:127-50.

4. Kechagioglou P, Papi RM, Provatopoulou X, Kalogera E, Papadimitriou E, Grigoropoulos P, et al. Tumor suppressor PTEN in breast cancer: heterozygosity, mutations and protein expression. Anticancer Res. 2014;34:1387-400.

5. Pandolfi PP. Breast cancer-loss of PTEN predicts resistance to treatment. N. Engl J Med. 2004;351:2337-8. 
6. Riese DJ 2nd, Stern DF. Specificity within the EGF family/ ErbB receptor family signaling network. BioEssays. 1998; 20:41-8.

7. Azim H, Azim HA Jr. Targeting Her-2/neu in breast cancer: as easy as this! Oncology. 2008;74:150-7.

8. van't Veer LJ, Dai H, van de Vijver MJ, He YD, Hart AA, Mao $\mathrm{M}$, et al. Gene expression profiling predicts clinical outcome of breast cancer. Nature 2002;415:530-6.

9. Nagata Y, Lan KH, Zhou X, Tan M, Esteva FJ, Sahin AA, et al. PTEN activation contributes to tumor inhibition by trastuzumab, and loss of PTEN predicts trastuzumab resistance in patients. Cancer Cell. 2004;6:117-27.

10. Fujita T, Doihara H, Kawasaki K, Takabatake D, Takahashi H, Washio $\mathrm{K}$, et al. PTEN activity could be a predictive marker of trastuzumab efficacy in the treatment of ErbB2-overexpressing breast cancer. Br J Cancer. 2006;94:247-52.

11. Cantley LC, Neel BG. New insights into tumor suppression: PTEN suppresses tumor formation by restraining the phosphoinositide 3-kinase/AKT pathway. Proc Natl Acad Sci USA. 1999;96:4240-5.

12. Simpson L, Parsons R. PTEN: life as a tumor suppressor. Exp Cell Res. 2001;264:29-41.

13. Shen WH, Balajee AS, Wang J, Wu H, Eng C, Pandolfi PP, et al. Essential role for nuclear PTEN in maintaining chromosomal integrity. Cell 2007;128:157-70.

14. Puc J, Parsons R. PTEN loss inhibits CHK1 to cause double stranded-DNA breaks in cells. Cell Cycle. 2005;4:927-9.

15. Trotman LC, Wang X, Alimonti A, Chen Z, Teruya-Feldstein J, Yang $\mathrm{H}$, et al. Ubiquitination regulates PTEN nuclear import and tumor suppression. Cell 2007;128:141-56.

16. Gupta A, Yang Q, Pandita RK, Hunt CR, Xiang T, Misri S, et al. Cell cycle checkpoint defects contribute to genomic instability in PTEN deficient cells independent of DNA DSB repair. Cell Cycle. 2009;8:2198-210.

17. Barnum KJ, O'Connell MJ. Cell cycle regulation by checkpoints. Methods Mol Biol. 2014;1170:29-40.

18. Hoeijmakers JH. Genome maintenance mechanisms for preventing cancer. Nature 2001;411:366-74.

19. Bartek J, Lukas J. DNA damage checkpoints: from initiation to recovery or adaptation. Curr Opin Cell Biol. 2007;19:238-45.

20. Shiloh Y. ATM and related protein kinases: safeguarding genome integrity. Nat Rev Cancer. 2003;3:155-68.

21. Lukas J, Lukas C, Bartek J. Mammalian cell cycle checkpoints: signalling pathways and their organization in space and time. DNA Repair. 2004;3:997-1007.

22. Bartek J, Lukas C, Lukas J. Checking on DNA damage in S phase. Nat Rev Mol Cell Biol. 2004;5:792-804.

23. Kastan MB, Bartek J. Cell-cycle checkpoints and cancer. Nature 2004:432:316-23.

24. Smith J, Tho LM, Xu N, Gillespie DA. The ATM-Chk2 and ATRChk1 pathways in DNA damage signaling and cancer. Adv Cancer Res. 2010;108:73-112.

25. Campisi J, d'Adda di Fagagna F. Cellular senescence: when bad things happen to good cells. Nat Rev Mol Cell Biol. 2007;8:729-40.

26. Halazonetis TD, Gorgoulis VG, Bartek J. An oncogene-induced DNA damage model for cancer development. Science 2008;319:1352-5.

27. Bassi C, Ho J, Srikumar T, Dowling RJ, Gorrini C, Miller SJ, et al. Nuclear PTEN controls DNA repair and sensitivity to genotoxic stress. Science 2013;341:395-9.

28. Andrechek ER, Hardy WR, Siegel PM, Rudnicki MA, Cardiff RD, Muller WJ. Amplification of the neu/erbB-2 oncogene in a mouse model of mammary tumorigenesis. Proc Natl Acad Sci USA. 2000;97:3444-9.
29. Hakem R, de la Pompa JL, Sirard C, Mo R, Woo M, Hakem A, et al. The tumor suppressor gene Brcal is required for embryonic cellular proliferation in the mouse. Cell. 1996;85:1009-23.

30. Farley FW, Soriano P, Steffen LS, Dymecki SM. Widespread recombinase expression using FLPeR (flipper) mice. Genesis. 2000;28:106-10.

31. Morgenstern JP, Land H. Advanced mammalian gene transfer: high titre retroviral vectors with multiple drug selection markers and a complementary helper-free packaging cell line. Nucleic Acids Res. 1990;18:3587-96.

32. Vichai V, Kirtikara K. Sulforhodamine B colorimetric assay for cytotoxicity screening. Nat Protoc. 2006;1:1112-6.

33. Weinstock DM, Nakanishi K, Helgadottir HR, Jasin M. Assaying double-strand break repair pathway choice in mammalian cells using a targeted endonuclease or the RAG recombinase. Methods Enzymol. 2006;409:524-40.

34. Guy CT, Webster MA, Schaller M, Parsons TJ, Cardiff RD, Muller WJ. Expression of the neu protooncogene in the mammary epithelium of transgenic mice induces metastatic disease. Proc Natl Acad Sci USA. 1992;89:10578-82.

35. Muller WJ, Sinn E, Pattengale PK, Wallace R, Leder P. Singlestep induction of mammary adenocarcinoma in transgenic mice bearing the activated c-neu oncogene. Cell 1988;54:105-15.

36. Sharma A, Singh K, Almasan A. Histone H2AX phosphorylation: a marker for DNA damage. Methods Mol Biol. 2012;920:613-26.

37. Soule HD, Maloney TM, Wolman SR, Peterson WD Jr, Brenz R, McGrath $\mathrm{CM}$, et al. Isolation and characterization of a spontaneously immortalized human breast epithelial cell line, MCF-10. Cancer Res. 1990;50:6075-86.

38. Guan J, Zhao Q, Mao W. Nuclear PTEN interferes with binding of $\mathrm{Ku} 70$ at double-strand breaks through post-translational poly(ADPribosyl)ation. Biochim. Biophys. Acta. 2016;1863:3106-15.

39. Reich M, Liefeld T, Gould J, Lerner J, Tamayo P, Mesirov JP. GenePattern 2.0. Nat Genet. 2006;38:500-1.

40. Bacevic K, Lossaint G, Achour TN, Georget V, Fisher D, Dulic V. Cdk2 strengthens the intra-S checkpoint and counteracts cell cycle exit induced by DNA damage. Sci Rep. 2017;7:13429.

41. Galea CA, Nourse A, Wang Y, Sivakolundu SG, Heller WT, Kriwacki RW. Role of intrinsic flexibility in signal transduction mediated by the cell cycle regulator, p27 Kip1. J Mol Biol. 2008;376:827-38.

42. Pagano M, Tam SW, Theodoras AM, Beer-Romero P, Del Sal G, Chau V, et al. Role of the ubiquitin-proteasome pathway in regulating abundance of the cyclin-dependent kinase inhibitor p27. Science 1995;269:682-5

43. Fujita N, Sato S, Katayama K, Tsuruo T. Akt-dependent phosphorylation of p27Kip1 promotes binding to 14-3-3 and cytoplasmic localization. J Biol Chem. 2002;277:28706-13.

44. Rahdar M, Inoue T, Meyer T, Zhang J, Vazquez F, Devreotes PN. A phosphorylation-dependent intramolecular interaction regulates the membrane association and activity of the tumor suppressor PTEN. Proc Natl Acad Sci USA. 2009;106:480-5.

45. Bolduc D, Rahdar M, Tu-Sekine B, Sivakumaren SC, Raben D, Amzel LM, et al. Phosphorylation-mediated PTEN conformational closure and deactivation revealed with protein semisynthesis. eLife 2013;2:e00691.

46. Fry EA, Taneja P, Inoue K. Clinical applications of mouse models for breast cancer engaging HER2/neu. Integr Cancer Sci Ther. 2016;3:593-603.

47. Li B, Rosen JM, McMenamin-Balano J, Muller WJ, Perkins AS. neu/ERBB2 cooperates with p53-172H during mammary tumorigenesis in transgenic mice. Mol Cell Biol. 1997;17:3155-63.

48. Guan X, Wang Y, Xie R, Chen L, Bai J, Lu J, et al. p27(Kip1) as a prognostic factor in breast cancer: a systematic review and metaanalysis. J Cell Mol Med. 2010;14:944-53. 
49. Liang J, Zubovitz J, Petrocelli T, Kotchetkov R, Connor MK, Han $\mathrm{K}$, et al. PKB/Akt phosphorylates p27, impairs nuclear import of p27 and opposes p27-mediated G1 arrest. Nat Med. 2002;8:1153-60.

50. Zhao H, Faltermeier CM, Mendelsohn L, Porter PL, Clurman BE, Roberts JM. Mislocalization of p27 to the cytoplasm of breast cancer cells confers resistance to anti-HER2 targeted therapy. Oncotarget 2014;5:12704-14.

51. Visconti R, Della Monica R, Grieco D. Cell cycle checkpoint in cancer: a therapeutically targetable double-edged sword. J Exp Clin Cancer Res. 2016;35:153. 